\title{
PENGARUH PRODUK DOMESTIK BRUTO (PDB) TERHADAP \\ PEMBIAYAAN BANK UMUM SYARIAH (BUS) DAN UNIT USAHA SYARIAH (UUS) TAHUN 2010-2014 (PENERAPAN ANALISIS REGRESI DATA POOLING)
}

\author{
Oleh : Hamni Fadlilah Nasution, M.Pd
}

hamnifadlilahnasution@gmail.com \& hamnifadlilahnasution@ymail.com

\begin{abstract}
The main function of BUS / UUS is not much different from conventional banks that collect funds from the public and then channel them back (intermediate). In practice, Islamic banks channeling funds it received in the form of financing, both venture capital financing as well as for consumption. Financing is providing facilities for provision of funds to support the planned investment is based on an agreement between the bank and other parties who require the financed party to return the money or the charges after a certain period of time in exchange or for the results. This study aims to determine the effect of gross domestic product to finance the BUS / UUS. The data used pooling is data. Data pooling with the category of 5 years and 9 sectors studied. analysis is the result of estimation fixed effect. The results showed PBD affect the financing BUS / UUS., the effect on the GDP amounted to 95.68 percent financing. As well as the remaining amount of 4.32 percent is influenced by other variables not examined in this study. The most high-elasticity sector financing is LGA sector (electricity, gas and water), while the lowest elasticity IDS financing is a sector (manufacturing industry)
\end{abstract}

\section{A. Pendahuluan}

Bank merupakan salah satu lembaga keuangan yang kegiatannya menghimpun dana dari masyarakat dan menyalurkan dana kepada masyarakat. Menghimpun dana dari masyarakat berupa tabungan, giro dan deposito adalah kegiatan utama dari bank. Salah satu kegiatan bank yang berperan dalam meningkatkan taraf hidup masyarakat adalah bank menjadi tempat untuk meminjamkan uang (kredit) bagi masyarakat yang membutuhkan dana, selain kegiatan lainnya seperti tempat tukar menukar uang, memindahkan uang, menerima segala bentuk pembayaran dan setoran. ${ }^{1}$ 


\section{PENGARUH PRODUK DOMESTIK BRUTO (PDB) TERHADAP PEMBIAYAAN BANK UMUM SYARIAH (BUS) DAN UNIT USAHA \\ SYARIAH (UUS) TAHUN 2010-2014 \\ (PENERAPAN ANALISIS REGRESI DATA POOLING)}

Bank adalah badan usaha yang menghimpun dana dari masyarakat dalam bentuk simpanan dan menyalurkan kepada masyarakat dalam bentuk kredit dan atau dalam bentuk-bentuk lainnya, dalam rangka meningkatkan taraf hidup rakyat banyak. ${ }^{2}$ Perbankan syariah saat ini menunjukkan eksistensinya sebagai lembaga keuangan yang dapat menghimpun dan menyalurkan dana masyarakat. Krisis moneter yang terjadi pada tahun 1998 telah menenggelamkan bank-bank konvensional dan banyak yang dilikuidasi karena kegagalan sistem bunga.

Lembaga keuangan syariah kembali membuktikan daya tahannya dari terpaan krisis ketika terjadi krisis global yang melanda dunia pada penghujung akhir tahun 2008. Lembaga-lembaga keuangan syariah tetap stabil dan memberikan keuntungan, kenyamanan serta keamanan bagi para pemegang sahamnya, pemegang surat berharga, peminjam dan para penyimpan dana di bank-bank syariah. Hal ini, dapat dibuktikan dari keberhasilan Bank Muamalat melewati krisis yang terjadi pada tahun 1998 dengan menunjukkan kinerja yang semakin meningkat dan tidak menerima sepeser pun bantuan dari pemerintah dan pada krisis keuangan tahun 2008, Bank Muamalat bahkan mampu memperoleh laba Rp. 300 miliar lebih.

Perbankan syariah selaku lembaga keuangan yang berasaskan keadilan, kemitraan, transparansi dan universal serta melakukan kegiatan usaha perbankan berdasarkan prinsip perekonomian Islam. Kegiatan usaha perbankan syariah mempunyai ciri khas antara lain mengharamkan riba, konsep uang sebagai alat tukar bukan sebagai komoditas dan tidak dipekenankan melakukan kegiatan spekulasi dalam berbagai bentuknya. Bagi Hasil adalah sebuah bentuk pengembalian dari kontrak investasi, berdasarkan suatu periode tertentu dengan karakteristiknya yang tidak tetap dan tidak pasti besar kecilnya perolehan tersebut.

Perbankan syariah meliputi Bank Umum Syariah, Unit Usaha Syariah dan Bank Perkreditan Rakyat Syariah. Bank Umum Syariah (BUS) adalah bank syariah yang dalam kegiatannya memberikan jasa dalam lalu lintas pembayaran. Unit Usaha Syariah (UUS) adalah unit kerja dari kantor 
pusat bank umum konvensional yang berfungsi sebagai kantor induk dari kantor atau unit yang melaksanakan kegiatan usaha berdasarkan prinsip syariah, atau unit kerja di kantor cabang dari suatu bank yang berkedudukan di luar negeri yang melaksanakan kegiatan usaha secara konvensional yang berfungsi sebagai kantor induk dari kantor cabang pembantu syariah dan/atau unit syariah ${ }^{3}$.

Di tengah kondisi ekonomi yang belum stabil, pada tahun ini sektor perbankan syariah di Indonesia diprediksi dapat tumbuh lebih tinggi. Diperkirakan, bank umum syariah (BUS) dan unit usaha syariah (UUS) masih mencatatkan pertumbuhan signifikan di tahun ini. "Hal itu terkait dengan telah rampungnya proses konsolidasi dua BUS terbesar dengan nilai mencapai Rp15 triliun-Rp20 triliun $^{4}$

Pembiayaan yang disalurkan BUS/UUS terbagi juga dalam sektorsektor ekonomi. Adapun pembiayaan BUS/UUS dibagi ke dalam sembilan sektor yaitu : 1) Sektor pertanian, kehutanan dan sarana pertanian, 2) Sektor pertambangan, 3) Sektor perindustrian, 4) Sektor listrik, gas dan air, 5) Sektor konstruksi, 6) Perdagangan, restoran dan hotel, 7) Pengangkutan, pergudangan dan komunikasi 8) Jasa dunia usaha dan 9) Jasa sosial dan masyarakat + sektor lain-lain. ${ }^{5}$

Pembiayaan yang disalurkan berdasarkan kesembilan sektor tersebut erat kaitannya dengan produk domestik bruto. Sesuai dengan penelitian yang dilakukan oleh Sihombing (2010) dinyatakan bahwa dengan meningkatnya pertumbuhan PDB maka dapat memicu pertumbuhan kredit yang disalurkan oleh bank. ${ }^{6}$ Pendapat tersebut berbeda dengan hasil penelitian yang dilakukan oleh Mahayoga dan Yuliarmi (2012) yang menyatakan bahwa PDRB tidak berpengaruh signifikan terhadap penyaluran kredit. ${ }^{7}$

\section{B. Pembahasan}

\section{Pembiayaan}

Salah satu fungsi utama BUS/UUS yaitu menghimpun dana dari masyarakat kemudian menyalurkannya kembali (intermediasi). Dalam 


\section{PENGARUH PRODUK DOMESTIK BRUTO (PDB) TERHADAP \\ PEMBIAYAAN BANK UMUM SYARIAH (BUS) DAN UNIT USAHA \\ SYARIAH (UUS) TAHUN 2010-2014 \\ (PENERAPAN ANALISIS REGRESI DATA POOLING)}

prakteknya bank syariah menyalurkan dana yang diperolehnya dalam bentuk pemberian pembiayaan, baik itu pembiayaan modal usaha maupun untuk konsumsi. Pembiayaan merupakan pemberian fasilitas penyediaan dana untuk mendukung investasi yang telah direncanakan berdasarkan kesepakatan antara bank dengan pihak lain yang mewajibkan pihak yang dibiayai untuk mengembalikan uang atau tagihan tersebut setelah jangka waktu tertentu dengan imbalan atau bagi hasil.

Menurut M. Syafii Antonio Pembiayaan adalah pemberian fasilitas penyediaan dana untuk memenuhi kebutuhan pihak-pihak yang merupakan defisit unit ${ }^{8}$. Menurut Muhammad Pembiayaan dalam secara luas diartikan sebagai pendanaan yang di keluarkan untuk mendukung investasi yang telah direncanakan baik dilakukan sendiri maupun dijalankan oleh orang lain. ${ }^{9}$ Pembiayaan adalah penyediaan uang atau tagihan yang dipersamakan dengan itu berdasarkan persetujuan atau kesepakatan antara bank dengan pihak lain yang mewajibkan pihak yang dibiayai untuk mengembalikan uang atau tagihan tersebut setelah jangka waktu tertentu dengan imbalan atau bagi hasil. ${ }^{10}$

Berdasarkan pengertian tersebut diatas, dapat disimpulkan bahwa pembiayaan adalah pemberian fasilitas penyediaan dana dari pihak BUS/UUS untuk mendukung investasi yang telah direncanakan berdasarkan kesepakatan antara bank dengan pihak lain yang mewajibkan pihak yang dibiayai untuk mengembalikan uang atau tagihan tersebut setelah jangka waktu tertentu dengan imbalan atau bagi hasil.

Pembiayaan merupakan salah satu tugas pokok Bank Syariah, yaitu pemberian fasilitas penyediaan dana untuk memenuhi kebutuhan pihak-pihak yang membutuhkan pembiayaan.Menurut sifat penggunaannya pembiayaan dapat dibagi menjadi 2 (dua) hal berikut :

a. Pembiayaan produktif, yaitu pembiayaan yang ditujukan untuk memenuhi kebutuhan produksi dalam arti luas, yaitu untuk peningkatan usaha, baik usaha produk perdagangan maupun investasi. 
b. Pembiayaan konsumtif, yaitu pembiayaan yang digunakan untuk memenuhi kebutuhan konsumsi yang akan habis digunakan. Kebutuhan konsumsi dapat dibedakan atas 2 (dua), yaitu diantaranya : Kebutuhan primer, adalah kebutuhan pokok, baik berupa barang, seperti makanan, minuman, pakaian dan tempat tinggal maupun berupa jasa, seperti pendidikan dasar dan pengobatan. Kebutuhan sekunder, adalah kebutuhan tambahan yang secara kwantitatif maupun kualitatif lebih tinggi atau lebih mewah dari kebutuhan primer, baik berupa barang, seperti bangunan rumah, kendaraan, perhiasan maupun jasa seperti pendidikan, pariwisata, hiburan dan sebagainya. ${ }^{11}$

\section{Produk Domestik Bruto (PDB)}

Penentuan kondisi ekonomi suatu negara dapat ditentukan dengan indikator tertentu. Salah satu indikator telah terjadinya alokasi yang efisien secara makro adalah nilai output nasional yang dihasilkan sebuah perekonomian pada suatu periode tertentu. ${ }^{12}$ Salah satu indikator untuk mengetahu kondisi ekonomi di suatu negara dalam periode tertentu adalah data produk domestik bruto (PDB), baik atas dasar harga berlaku maupun atas dasar harga konstan. PDB adalah jumlah nilai tambah yang dihasilkan oleh seluruh unit usaha dalam suatu negara atau jumlah unit barang atau jasa akhir yang dihasilkan oleh seluruh unit ekonomi. PDB atas harga berlaku menggambarkan nilai tambah barang atau jasa yang dihitung menggunakan harga yang berlaku pada setiap tahun, sedangkan PDB atas dasar harga konstan menunjukkan nilai tambah barang dan jasa tersebut dihitung menggunakan harga yang berlaku pada satu tahun tertentu sebagai dasar. Disimpulkan PDB dapat digunkan untuk melihat pergeseran dan struktur ekonomi $^{13}$

PDB ialah barang dan jasa akhir, tidak dimasukkan barang yang sudah terpakai dan transaksi surat berharga serta tidak dimasukkan juga keluaran yang diproduksi di luar negeri oleh faktor produksi yang dimiliki dalam negeri. ${ }^{14}$ Jadi, PDB adalah jumlah (nilai uang) dari semua barang dan jasa "final" yang dihasilkan selama satu tahun di dalam batas-batas negara 


\section{PENGARUH PRODUK DOMESTIK BRUTO (PDB) TERHADAP \\ PEMBIAYAAN BANK UMUM SYARIAH (BUS) DAN UNIT USAHA \\ SYARIAH (UUS) TAHUN 2010-2014 \\ (PENERAPAN ANALISIS REGRESI DATA POOLING)}

Kesatuan Republik Indonesia, yang dihitung menurut lapangan usaha atas dasar harga pasar dengan cara tambahan nilai. ${ }^{15}$

\section{Analisis Data dan Hasil Penelitian}

Data panel adalah kombinasi data time series dan cross section. Data dalam penelitian ini menggunakan data panel dengan data gabungan unit cross section 9 sektor dan unit time series sebanyak 5 tahun yaitu 20102014. Menurut Widarjono terdapat beberapa metode yang biasa digunakan dalam mengestimasi model regresi dengan data panel, yaitu pooling least square (Common Effect), pendekatan efek tetap (Fixed Effect), pendekatan efek random (Random Effect). ${ }^{16}$

Regresi data panel harus melalui tahapan penentuan model estimasi yang tepat. Berikut diagram tahapan dari regresi data panel:

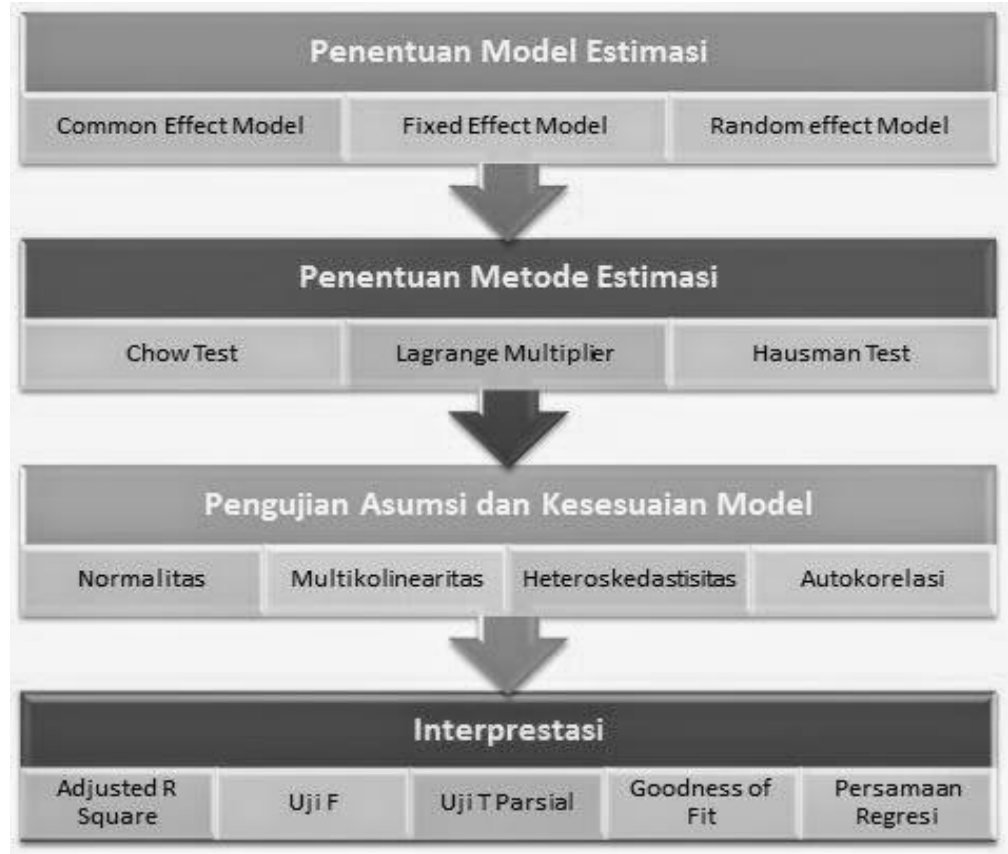

Gambar 1 : Tahapan Regresi Data Panel

Dalam metode estimasi model regresi dengan menggunakan data panel dapat dilakukan melalui tiga pendekatan, antara lain: ${ }^{17}$

a. Common Effect Model atau Pooled Least Square (PLS): Pendekatan model data panel yang paling sederhana karena hanya mengkombinasikan data time series dan cross section. Metode ini bisa 
menggunakan pendekatan Ordinary Least Square (OLS) atau teknik kuadrat terkecil untuk mengestimasi model data panel.

b. Fixed Effect Model (FE): Model ini mengasumsikan bahwa perbedaan antar individu dapat diakomodasi dari perbedaan intersepnya. Untuk mengestimasi data panel model Fixed Effects menggunakan teknik variable dummy untuk menangkap perbedaan intersep antar perusahaan, perbedaan intersep bisa terjadi karena perbedaan budaya kerja, manajerial, dan insentif. Namun demikian slopnya sama antar perusahaan. Model estimasi ini sering juga disebut dengan teknik Least Squares Dummy Variable (LSDV).

c. Random Effect Model (RE): Model ini akan mengestimasi data panel dimana variabel gangguan mungkin saling berhubungan antar waktu dan antar individu. Pada model Random Effect perbedaan intersep diakomodasi oleh error terms masing-masing perusahaan. Keuntungan menggunakan model Random Effect yakni menghilangkan heteroskedastisitas. Model ini juga disebut dengan Error Component Model (ECM) atau teknik Generalized Least Square (GLS) .

Untuk memilih model yang paling tepat terdapat beberapa pengujian yang dapat dilakukan, antara lain: ${ }^{18}$

a. Uji Chow : Chow test adalah pengujian untuk menentukan model Fixed Effet atau Random Effect yang paling tepat digunakan dalam mengestimasi data panel. Apabila Hasil $\mathrm{H}_{0}$ : Pilih PLS dan jika $\mathrm{H}_{1}$ : Pilih FE

b. Uji Hausman: Hausman test adalah pengujian statistik untuk memilih apakah model Fixed Effect atau Random Effect yang paling tepat digunakan. Apabila hasil $\mathrm{H}_{0}$ : Pilih $\mathrm{RE}$ dan jika $\mathrm{H}_{1}$ : Pilih FE

c. Uji Lagrange Multiplier: Uji Lagrange Multiplier (LM) adalah uji untuk mengetahui apakah model Random Effect lebih baik daripada metode Common Effect (OLS) digunakan. Apabila hasil jika $\mathrm{H}_{0}$ : Pilih PLS dan jika $\mathrm{H}_{1}$ : Pilih RE 


\section{PENGARUH PRODUK DOMESTIK BRUTO (PDB) TERHADAP \\ PEMBIAYAAN BANK UMUM SYARIAH (BUS) DAN UNIT USAHA \\ SYARIAH (UUS) TAHUN 2010-2014 \\ (PENERAPAN ANALISIS REGRESI DATA POOLING)}

Dari ketiga uji untuk menentukan Metode Estimasi di atas, digambarkan dalam grafik di bawah ini:

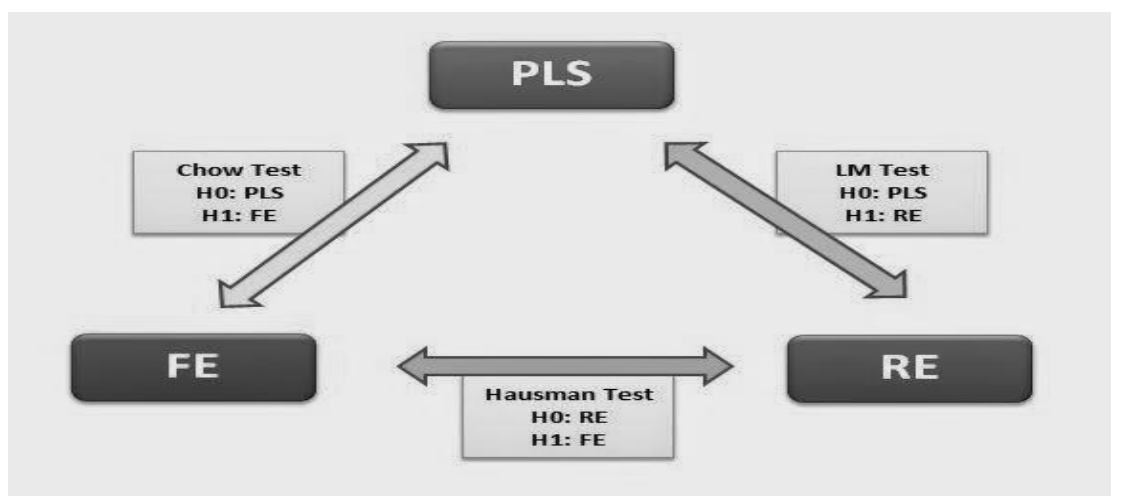

Gambar 2 : Penentuan Metode Estimasi

Berikut adalah hasil regresi data panel dari data PDRB dan Pembiayaan BUS dan UUS dari tahun 2010-2014. Untuk melihat pengaruh PDRB terhadap pembiayaan yang dikeluarkan BUS dan UUS

Tabel 1: Hasil Estimasi Common Effect

\begin{tabular}{lrlll}
\hline \hline \multicolumn{1}{c}{ Variable } & Coefficient & Std. Error & t-Statistic & Prob. \\
\hline \hline \multicolumn{1}{c}{ PDRB? } & 0.725312 & 0.014304 & 50.70671 & 0.0000 \\
\hline \hline R-squared & -0.032706 & Mean dependent var & 3.883839 \\
Adjusted R-squared & -0.032706 & S.D. dependent var & 0.505471 \\
S.E. of regression & 0.513670 & Akaike info criterion & 1.527501 \\
Sum squared resid & 11.60971 & Schwarz criterion & 1.567649 \\
Log likelihood & -33.36878 & Hannan-Quinn criter. & 1.542468 \\
Durbin-Watson stat & 0.089925 & & \\
\hline \hline
\end{tabular}

Tabel 2: Hasil Estimasi Fixed Effect

\begin{tabular}{crrrr}
\hline \hline Variable & Coefficient & Std. Error & t-Statistic & Prob. \\
\hline \hline C & -19.76642 & 2.521997 & -7.837608 & 0.0000 \\
PDRB? & 4.430724 & 0.472468 & 9.377821 & 0.0000 \\
Fixed Effects & & & & \\
(Cross) & & & & \\
_PTN--C & -1.209949 & & & \\
_PTB--C & -0.295338 & & & \\
_IDS--C & -2.325315 & & & \\
_LGA--C & 4.185022 & & & \\
_BGN--C & 0.429592 & & & \\
_PHR--C & -1.242358 & & &
\end{tabular}




$\begin{array}{lr}\text { _PKM--C } & -0.549529 \\ \text { _KPJ--C } & 0.384252 \\ \text { _JSL--C } & 0.623622\end{array}$

Effects Specification

Cross-section fixed (dummy variables)

\begin{tabular}{lclr}
\hline \hline R-squared & 0.956823 & Mean dependent var & 3.883839 \\
Adjusted R-squared & 0.945720 & S.D. dependent var & 0.505471 \\
S.E. of regression & 0.117765 & Akaike info criterion & -1.247123 \\
Sum squared resid & 0.485400 & Schwarz criterion & -0.845643 \\
Log likelihood & 38.06027 & Hannan-Quinn criter. & -1.097455 \\
F-statistic & 86.17912 & Durbin-Watson stat & 1.277601 \\
Prob(F-statistic) & 0.000000 & & \\
\hline \hline
\end{tabular}

Tabel 3: Hasil Estimasi Random Effect

\begin{tabular}{crrrr} 
Variable & Coefficient & Std. Error & t-Statistic & Prob. \\
\hline \hline C & -7.300975 & 1.672496 & -4.365317 & 0.0001 \\
PDRB? & 2.095403 & 0.311746 & 6.721514 & 0.0000 \\
Random Effects & & & & \\
(Cross) & & & & \\
_PTN--C & -0.787657 & & & \\
_PTB--C & -0.416327 & & & \\
_IDS--C & -1.174910 & & & \\
_LGA--C & 1.748776 & & & \\
_BGN--C & 0.180071 & & & \\
_PHR--C & -0.466991 & & & \\
_PKM--C & -0.347860 & & & \\
_KPJ--C & 0.530903 & & \\
_JSL--C & 0.733995 & & \\
\hline \hline
\end{tabular}

Effects Specification

\begin{tabular}{llll} 
& & S.D. & Rho \\
\hline \hline $\begin{array}{l}\text { Cross-section random } \\
\text { Idiosyncratic random }\end{array}$ & & 0.501386 & 0.9477 \\
& & 0.117765 & 0.0523 \\
\hline \hline & Weighted Statistics & \\
\hline \hline R-squared & 0.346335 & Mean dependent var & 0.405730 \\
Adjusted R-squared & 0.331133 & S.D. dependent var & 0.202772 \\
S.E. of regression & 0.165836 & Sum squared resid & 1.182565 \\
F-statistic & 22.78291 & Durbin-Watson stat & 0.668198 \\
Prob(F-statistic) & 0.000021 & & \\
\hline \hline
\end{tabular}




\section{PENGARUH PRODUK DOMESTIK BRUTO (PDB) TERHADAP \\ PEMBIAYAAN BANK UMUM SYARIAH (BUS) DAN UNIT USAHA \\ SYARIAH (UUS) TAHUN 2010-2014 \\ (PENERAPAN ANALISIS REGRESI DATA POOLING)}

Unweighted Statistics

\begin{tabular}{lrll}
\hline \hline R-squared & -1.994069 & Mean dependent var & 3.883839 \\
Sum squared resid & 33.65941 & Durbin-Watson stat & 0.023476 \\
\hline \hline
\end{tabular}

Dari hasil ketiga estimasi tersebut, kita harus lakukan pengujian lagi untuk memilih model mana yang akan kita pakai dalam menganalisis data dalam penelitian ini yaitu :

a. Uji Chow.

Uji antara Model dengan metode Fixed Effect VS Common/Pool Effect.

Kita pakai uji Chow. Kalau nanti hasilnya adalah terima hipotesis nol yaitu model terbaik adalah Common, maka pengujian kita selesai sampai disini saja. Akan tetapi, kalau hasilnya nanti adalah menolak hipotesis nol sehingga model terbaik yang terpilih antara Fixed dan Common adalah Fixed, maka pengujian kita masih berlanjut. Hasil pengujian nya adalah :

\begin{tabular}{lrrr}
\hline \hline Effects Test & Statistic & d.f. & Prob. \\
\hline \hline Cross-section F & 89.677259 & $(8,35)$ & 0.0000 \\
Cross-section Chi-square & 138.057482 & 8 & 0.0000 \\
\hline \hline
\end{tabular}

\begin{tabular}{lrlll}
\hline \hline \multicolumn{1}{c}{ Variable } & Coefficient & Std. Error & t-Statistic & Prob. \\
\hline \hline \multicolumn{1}{c}{ C } & 2.126424 & 0.966468 & 2.200200 & 0.0332 \\
PDRB? & 0.329240 & 0.180538 & 1.823660 & 0.0752 \\
\hline \hline R-squared & 0.071790 & Mean dependent var & 3.883839 \\
Adjusted R-squared & 0.050204 & S.D. dependent var & 0.505471 \\
S.E. of regression & 0.492619 & Akaike info criterion & 1.465265 \\
Sum squared resid & 10.43496 & Schwarz criterion & 1.545561 \\
Log likelihood & -30.96847 & Hannan-Quinn criter. & 1.495199 \\
F-statistic & 3.325735 & Durbin-Watson stat & 0.109115 \\
Prob(F-statistic) & 0.075159 & & \\
\hline \hline
\end{tabular}

Nilai prob cross-section F, jika > 0,05 maka model yang terpilih adalah common-effect dan jika $<0,05$ maka model yang dipilih adalah fixed-effect. 
Untuk hasil penelitian ini maka : prob cross-section $\mathrm{F}$ nya adalah $0,0000<$ 0,05, maka pemilihan modelnya adalah fixed-effect

b. Uji Hausman

Menguji antara Random VS Fixed disini kita pakainya Uji Hausman. Ingat, hipotesis yang dipakai selalu pada hipotesis alternatif model terbaik adalah model Fixed Effect. Hasil pengujiannya adalah :

\begin{tabular}{llcc}
\hline \hline Test Summary & $\begin{array}{c}\text { Chi-Sq. } \\
\text { Statistic Chi-Sq. }\end{array}$ & \multicolumn{1}{c}{ d.f. } & Prob. \\
\hline \hline Cross-section random & 43.269441 & 1 & 0.0000 \\
\hline \hline
\end{tabular}

Cross-section random effects test comparisons:

\begin{tabular}{ccccc} 
Variable & Fixed & Random & Var(Diff.) & Prob. \\
\hline \hline PDRB? & 4.430724 & 2.095403 & 0.126041 & 0.0000 \\
\hline \hline Variable & Coefficient & Std. Error & t-Statistic & Prob. \\
\hline \hline C & -19.76642 & 2.521997 & -7.837608 & 0.0000 \\
PDRB? & 4.430724 & 0.472468 & 9.377821 & 0.0000 \\
\hline \hline
\end{tabular}

Cross-section fixed (dummy variables)

\begin{tabular}{lllr}
\hline \hline R-squared & 0.956823 & Mean dependent var & 3.883839 \\
Adjusted R-squared & 0.945720 & S.D. dependent var & 0.505471 \\
S.E. of regression & 0.117765 & Akaike info criterion & -1.247123 \\
Sum squared resid & 0.485400 & Schwarz criterion & -0.845643 \\
Log likelihood & 38.06027 & Hannan-Quinn criter. & -1.097455 \\
F-statistic & 86.17912 & Durbin-Watson stat & 1.277601 \\
Prob(F-statistic) & 0.000000 & & \\
\hline \hline
\end{tabular}

Nilai prob. Cross-section randomnya jika nilainya $>0,05$ maka model yang terpilih adalah random-effect. Jika $<0,05$ maka model yang terpilih adalah fixed-effect $0,0000<0,05$ maka model yang terpilih adalah fixed-effect. Berdasarkan hasil Uji Chow dan Uji hausman, model yang terpilih untuk penelitian ini adalah model Fixed-Effect. 


\section{PENGARUH PRODUK DOMESTIK BRUTO (PDB) TERHADAP \\ PEMBIAYAAN BANK UMUM SYARIAH (BUS) DAN UNIT USAHA \\ SYARIAH (UUS) TAHUN 2010-2014 \\ (PENERAPAN ANALISIS REGRESI DATA POOLING)}

Uji normalitas bertujuan untuk menguji apakah dalam model regresi panel variabel-variabelnya berdistribusi normal atau tidak. Model regresi yang baik adalah memiliki distribusi data normal atau mendekati normal. Dalam software EViews normalitas sebuah data dapat diketahui dengan membandingkan nilai Jarque-Bera (JB) dan nilai Chi Square tabel. Jika hasil dari JB hitung > Chi Square tabel, maka DATA TIDAK TERDISTRUSI NORMAL dan sebaliknya. Berdasarkan hasil pengujian normalitas yang dilakukan, maka hasil JB nya terlihat berikut ini :

Tabel 4 : Uji Normalitas

\begin{tabular}{|c|c|c|c|c|c|c|}
\hline & $\begin{array}{l}\text { PEMBIAY } \\
\text { AAN_PTN }\end{array}$ & $\begin{array}{c}\text { PEMBIAYAA } \\
\text { N_PTB }\end{array}$ & $\begin{array}{c}\text { PEMBIAYAA } \\
\text { N_IDS }\end{array}$ & $\begin{array}{c}\text { PEMBIAYAA } \\
\text { N_LGA }\end{array}$ & $\begin{array}{c}\text { PEMBIAYAA } \\
\text { N_BGN }\end{array}$ & \\
\hline Mean & 3.458601 & 3.350237 & 3.716552 & 3.483265 & 3.843793 & \\
\hline Median & 3.448552 & 3.320977 & 3.699664 & 3.499550 & 3.853820 & \\
\hline Maximum & 3.754272 & 3.662475 & 4.123852 & 3.739731 & 4.067034 & \\
\hline Minimum & 3.246006 & 3.049218 & 3.368659 & 3.131619 & 3.622628 & \\
\hline Std. Dev. & 0.192121 & 0.233530 & 0.275021 & 0.242596 & \multirow{2}{*}{0.164865} & \\
\hline \multirow[t]{2}{*}{ Jarque-Bera } & 0.396955 & 0.254996 & 0.189259 & 0.404444 & & \\
\hline & $\begin{array}{l}\text { PEMBIAY } \\
\text { AAN_PHR }\end{array}$ & $\begin{array}{l}\text { PEMBIAY } \\
\text { AAN_PKM }\end{array}$ & $\begin{array}{c}\text { PEMBIAYAA } \\
\text { N_KPJ }\end{array}$ & $\begin{array}{c}\text { PEMBIAYAA } \\
\text { N_JSL }\end{array}$ & & \\
\hline Mean & 4.102782 & 3.709648 & 4.557440 & 4.732233 & & \\
\hline Median & 4.101197 & 3.635584 & 4.569959 & 4.742757 & & \\
\hline Maximum & 4.385374 & 4.086075 & 4.824841 & 4.963141 & & \\
\hline Minimum & 3.881328 & 3.527501 & 4.306060 & 4.412914 & & \\
\hline Std. Dev. & 0.189982 & 0.224149 & 0.207001 & 0.209668 & & \\
\hline Jarque-Bera & 0.302182 & 1.017549 & 0.371689 & 0.386964 & & \\
\hline & \multicolumn{2}{|c|}{ PDRB PTN } & PDRB_PTB & PDRB_IDS & PDRB_LGA & $\begin{array}{c}\text { PDRB_BG } \\
\mathrm{N}\end{array}$ \\
\hline Mean & \multicolumn{2}{|c|}{$5.514 \overline{4894}$} & 5.284012 & 5.824847 & 4.302833 & 5.231791 \\
\hline Median & \multicolumn{2}{|c|}{5.516244} & 5.285870 & 5.826198 & 4.303066 & 5.232703 \\
\hline Maximum & \multicolumn{2}{|c|}{5.544963} & 5.291931 & 5.870308 & 4.350703 & 5.288011 \\
\hline Minimum & \multicolumn{2}{|c|}{5.483982} & 5.272196 & 5.776072 & 4.256482 & 5.176156 \\
\hline Std. Dev. & \multicolumn{2}{|c|}{0.024452} & 0.008347 & 0.037385 & 0.037889 & 0.044654 \\
\hline Jarque-Bera & \multicolumn{2}{|c|}{0.390067} & 0.518454 & 0.363766 & 0.394637 & 0.377123 \\
\hline & $\begin{array}{c}\text { PDRB_P } \\
\text { HR }\end{array}$ & $\begin{array}{c}\text { PDRB_PK } \\
M\end{array}$ & PDRB_KPJ & PDRB_JSL & & \\
\hline Mean & 5.667598 & 5.422499 & 5.403092 & 5.388517 & & \\
\hline Median & 5.675001 & 5.423874 & 5.403121 & 5.388824 & & \\
\hline Maximum & 5.719588 & 5.503147 & 5.459921 & 5.436947 & & \\
\hline Minimum & 5.602575 & 5.338417 & 5.344440 & 5.338142 & & \\
\hline Std. Dev. & 0.046737 & 0.065066 & 0.046285 & 0.038430 & & \\
\hline Jarque-Bera & 0.412559 & 0.351012 & 0.386917 & 0.309667 & & \\
\hline
\end{tabular}

Nilai Chi Square dengan melihat jumlah variabel independen yang

kita pakai dalam hal ini 1 variabel independen dan nilai signifikan yang kita pakai dalam hal ini 0,05 atau 5\%. Didapat nilai Chi Square sebesar 3,84. Berdasarkan tabel di atas, nilai JB pada pembiayaan tiap sektor dan PDB 
tiap sektor berada di bawah nilai 3,84, artinya data pembelian dan data pdrb dalam penelitian ini terdistribusi normal.

Berdasarkan hasil Uji Chow dan Uji Hausman, maka yang akan kita analisis adalah hasil dari estimasi FIXED EFFECT, yaitu :

\begin{tabular}{crrrr}
\hline \hline Variable & Coefficient & Std. Error & t-Statistic & Prob. \\
\hline \hline C & -19.76642 & 2.521997 & -7.837608 & 0.0000 \\
PDRB? & 4.430724 & 0.472468 & 9.377821 & 0.0000 \\
Fixed Effects & & & & \\
(Cross) & & & & \\
_PTN--C & -1.209949 & & & \\
_PTB--C & -0.295338 & & & \\
_IDS--C & -2.325315 & & \\
_LGA--C & 4.185022 & & \\
_BGN--C & 0.429592 & & \\
_PHR--C & -1.242358 & & \\
_PKM--C & -0.549529 & & \\
_KPJ--C & 0.384252 & & \\
_JSL--C & 0.623622 & & \\
\hline \hline
\end{tabular}

Cross-section fixed (dummy variables)

\begin{tabular}{lllr}
\hline \hline R-squared & 0.956823 & Mean dependent var & 3.883839 \\
Adjusted R-squared & 0.945720 & S.D. dependent var & 0.505471 \\
S.E. of regression & 0.117765 & Akaike info criterion & -1.247123 \\
Sum squared resid & 0.485400 & Schwarz criterion & -0.845643 \\
Log likelihood & 38.06027 & Hannan-Quinn criter. & -1.097455 \\
F-statistic & 86.17912 & Durbin-Watson stat & 1.277601 \\
Prob(F-statistic) & 0.000000 & & \\
\hline \hline
\end{tabular}

Model dalam penelitian in adalah : $\mathrm{Y}=\mathrm{a}+\mathrm{bX}$

Berdasarkan variabel penelitian, maka persamaan yang terbentuk adalah :

PEMBIAYAAN $=a+b \log$ PDRB

sehingga berdasarkan hasil dari estimasi Fixed Effect, maka persamaan yang terbentuk adalah PEMBIAYAAN $=-19,76642+4,430724$ PDRB.

Dari hasil estimasi di dapat bahwa nilai R-squarednya adalah 0,956823. Artinya pengaruh PDB terhadap PEMBIAYAAN sebesar 95,68 persen. Serta sisanya sebesar 4,32 persen dipengaruhi oleh variable lain yang tidak 


\section{PENGARUH PRODUK DOMESTIK BRUTO (PDB) TERHADAP \\ PEMBIAYAAN BANK UMUM SYARIAH (BUS) DAN UNIT USAHA \\ SYARIAH (UUS) TAHUN 2010-2014 \\ (PENERAPAN ANALISIS REGRESI DATA POOLING)}

diteliti dalam penelitian ini. Dengan nilai intersep yang berbeda untuk tiap sektornya, yaitu :

$$
\begin{aligned}
& \text { PEMBIAYAAN_PTN }=-1.209949+4,430724 \text { PDRB } \\
& \text { PEMBIAYAAN_PTB }=-0.295338+4,430724 \text { PDRB } \\
& \text { PEMBIAYAAN_IDS }=-2.325315+4,430724 \text { PDRB } \\
& \text { PEMBIAYAAN_LGA }=4.185022+4,430724 \text { PDRB } \\
& \text { PEMBIAYAAN_BGN }=0.429592+4,430724 \text { PDRB } \\
& \text { PEMBIAYAAN_PHR }=-1.242358+4,430724 \text { PDRB } \\
& \text { PEMBIAYAAN_PKM }=-0.549529+4,430724 \text { PDRB } \\
& \text { PEMBIAYAAN_KPJ }=0.384252+4,430724 \text { PDRB } \\
& \text { PEMBIAYAAN_JSL }=0.623622+4,430724 \text { PDRB }
\end{aligned}
$$

Intersep yang berbeda in menyebabkan setiap sektor mempunyai elastisitas pembiayaan yang berbeda-beda jika dilakukan penambahan terhadap variabel-variabel yang mempengaruhinya. Berdasarkan besaran nilai intersepnya diperoleh kesimpulan bahwa sektor yang paling tinggi elastisitas pembiayaannya adalah sektor LGA (listrik, gas dan air), sedangkan yang paling rendah elastisitas pembiayaannya adalah sektor IDS (industri pengolahan).

\section{SIMPULAN}

Secara spesifik, terdapat beberapa faktor yang mempengaruhi usaha bank dalam pengalokasian dana dalam bentuk pembiayaan. Beberapa diantaranya adalah kondisi ekonomi (PDB, inflasi dan kurs valas) disamping kondisi internal keuangan bank tersebut. Sehingga kondisi perekonomian selalu menjadi perhatian perbankan dalam menyalurkan pembiayaan. Tujuannya agar pembiayaan yang disalurkan tidak berpotensi mengurangi likuiditas bank.

Ada 9 sektor yang menjadi acuan dalam PDB dan perbankan dalam menyalurkan pembiayaan. Dari kesembilan sektor tersebut yang paling tinggi elastisitasnya adalah sektor LGA (listrik, gas dan air). Sehingga sektor LGA menjadi prioritas dan sangat mempengaruhi perbankan dalam pemberian pembiayaan. Sehingga BUS dan UUS harus lebih 
mengutamakan pemberian pembiayaan kepada sektor listrik, gas dan air agar menarik minat investor atau masyarakat untuk menanamkan saham dan untuk menabung di BUS dan UUS.

Catatan :

${ }^{1}$ Djoko Muljono, Perbankan dan Lembaga Keuangan Syariah. 2015. (Yogyakarta: Penerbit Andi), hlm 416

2 Undang-Undang Republik Indonesia Nomor 10 Tahun 1998 tentang Perbankan

3 Undang-Undang Republik Indonesia Nomor 21 Tahun 2008 tentang Perbankan

${ }^{4}$ Direktur Karim Consulting, Adiwarman Karim di Jakarta, Kamis $(16 / 6 / 2016)$.

${ }^{5}$ www.ojk.go.id diakses pada tanggal, 12-08-2016, pukul 21.45 wib.

6 Sihombing, Binsar. Pengaruh Tingkat Suku Bunga Kredit Konsumsi, Intensitas Persaingan Bank, dan Pendapatan per Kapita terhadap permintaan kredit Konsumsi di Sumatera Utara. 2010. (Medan: Artikel Ekonomi Fakultas Ekonomi Universitas Katolik Santo Thomas SU). Medan. Hlm 492.

${ }^{7}$ Mahayoga, Gede Agus Dian dan Ni Nyoman Yuliarmi. 2012. Faktor-faktor yang mempengaruhi penyaluran kredit BPR di Provinsi Bali. E-Journal -Ekonomi Pembangunan.Vol.2 No.6.hal. 284-293. ISSN 23030178

${ }^{8}$ Muhammad Syafi'I Antonio.Bank Syariah dari Teori ke Praktik. . 2011.(Jakarta: Gema Insani) hlm 160

9 Muhamad, Manajemen Pembiayaan Bank Syariah, 2005 (Yogyakarta: Unit Penerbit dan Percetakan AMP YKPN,) hal. 17

${ }^{10}$ UU No. 10 tahun 1998 tentang Perbankan

${ }^{11}$ Op cit. hal. 168

12 N. Gregory Mankiw, Makroekonomi Edisi Enam (ed. Wibi Hardani, dkk.), (Jakarta: Erlangga, 2006), hlm. 17

${ }^{13}$ www.bps.go.id

${ }^{14}$ Karl E. Case dan Ray C. Fair, Prinsip-prinsip Ekonomi Makro Edisi Kelima, (Jakarta:PT. Indeks, 2009), hlm.25

15 T. Gilarso, Pengantar Ilmu Ekonomi Makro: Edisi Revisi, (Yogyakarta: Kanisius, 2004),

hal. 185.

${ }^{16}$ Widarjono. Agus . 2007. Ekonometrika Teori dan Aplikasi untuk Ekonomi dan Bisnis. Ekonisia. Yogyakarta

17 http://www.statistikian.com diakses pada tanggal 17-09-2016 pukul $23.00 \mathrm{wib}$

${ }^{18}$ Ibid 


\section{PENGARUH PRODUK DOMESTIK BRUTO (PDB) TERHADAP \\ PEMBIAYAAN BANK UMUM SYARIAH (BUS) DAN UNIT USAHA \\ SYARIAH (UUS) TAHUN 2010-2014 \\ (PENERAPAN ANALISIS REGRESI DATA POOLING)}

\section{DAFTAR PUSTAKA}

Djoko Muljono, Perbankan dan Lembaga Keuangan Syariah.Yogyakarta: Penerbit Andi.2015.

Undang-Undang Republik Indonesia Nomor 10 Tahun 1998 tentang Perbankan

Undang-Undang Republik Indonesia Nomor 21 Tahun 2008 tentang Perbankan

Direktur Karim Consulting, Adiwarman Karim di Jakarta, Kamis (16/6/2016). Sindocom diakses pada tanggal 25-10-2016, pukul $23.05 \mathrm{wib}$

www.ojk.go.id diakses pada tanggal, 12-08-2016, pukul 21.45 wib.

Sihombing, Binsar. Pengaruh Tingkat Suku Bunga Kredit Konsumsi, Intensitas Persaingan Bank, dan Pendapatan per Kapita terhadap permintaan kredit Konsumsi di Sumatera Utara. Medan: Artikel Ekonomi Fakultas Ekonomi Universitas Katolik Santo Thomas SU. 2010.

Mahayoga, Gede Agus Dian dan Ni Nyoman Yuliarmi. 2012. Faktor-faktor yang mempengaruhi penyaluran kredit BPR di Provinsi Bali. EJournal -Ekonomi Pembangunan.Vol.2 No.6.hal. 284-293. ISSN 2303-0178

Muhammad Syafi'I Antonio.Bank Syariah dari Teori ke Praktik. . Jakarta: Gema Insani.2011.

Muhamad, Manajemen Pembiayaan Bank Syariah.Yogyakarta: Unit Penerbit dan Percetakan AMP YKPN. 2005.

N. Gregory Mankiw, Makroekonomi Edisi Enam (ed. Wibi Hardani, dkk.), .Jakarta: Erlangga.2006

www.bps.go.id

Karl E. Case dan Ray C. Fair, Prinsip-prinsip Ekonomi Makro Edisi Kelima,Jakarta:PT. Indeks.2009.

T. Gilarso, Pengantar Ilmu Ekonomi Makro: Edisi Revisi, Yogyakarta: Kanisius.2004.

Widarjono. Agus . Ekonometrika Teori dan Aplikasi untuk Ekonomi dan Bisnis. Yogyakarta: Ekonisia..2007.

http://www.statistikian.com diakses pada tanggal 17-09-2016 pukul 23.00 wib 